\title{
DUAL VOICING OF ASIAN AMERICAN WRITERS: THE CASE OF AMY TAN
}

\author{
IGA MARIA LEHMAN
}

\section{Introduction}

The ways in which authorial identity is bound up with how people write and how their narratives are influenced by all the contextual factors (cultural, linguistic, physical, relational and perceptual) have been the subject of considerable research in such fields as discourse studies, textual linguistics and cultural studies. However, the key literature produced in these fields has failed to give sufficient consideration to such issues as the alienation, inadequacy and exclusion experienced by writers who do not align themselves with the 'dominant narratives' when writing about themselves and their lives. The capacity to narrate our personal experience gives us a sense of individual identity, but in so far as we are able to relate that experience to a broader narrative, we can also share an identity with others. Indeed, what defines people as credible writers is not the content of their stories, but the way they draw on socially available resources to tell them. How people use these resources is bluntly explained by Gee (1999: 2), "[w]hen we speak or write we always take a particular perspective on what is "normal" and not; what is "acceptable" and not, what is "right" and not, what is "real" and not; what is the "way things are" and not; what is the "way things ought to be" and not; what is "possible" and not; what "people like us" or "people like them" do and don't; and so on and so forth, again through a nearly endless list." Consequently, writer textual self-representation becomes the outcome of discourse-situated processes of attribution and negotiation over identities.

It often happens, however, that identity establishes itself not only in relation to similarity, but also in relation to difference, when other identities and relation- 
ships are being rejected. The problem of conflicting identities is seen in the texts of writers who do not define themselves in terms of absolute similarity shared with other group members. Some aspects of their authorial self contradict each other in different ways, influencing the linguistic, rhetorical and stylistic choices they make in their texts.

The textual realization of authorial identity is, therefore, the outcome of different types of social positioning and becomes even more intricate when a writer has to write in "the space between" two languages and two cultures. This is the case of bicultural authors, such as Amy Tan (an American writer of Chinese origin) who struggles to reconcile the requirements of Anglo-American linear reasoning with an East-Asian expansive logic.

Taking Lanigan (2012) typology of East-Asian and Western cultures as a point of departure for ruminations on what happens when a writer's life experience brings one culture into contact with another, I claim that due to such cross-cultural exposure a writer acquires dual perception of reality which allows them to see two constructs of reality instead of one.

The authorial identity of such a bicultural writer is not, however, a unitary construct as it comprises two different and psychometrically independent components. Benet-Martínez and Haritatos (2005) divide them into two categories:

(a) cultural blendedness versus compartmentalization- the degree of dissociation versus overlap perceived between the two cultural orientations (e.g., "I see myself as a Chinese in the United States" vs. "I am a ChineseAmerican"),

(b) cultural harmony versus conflict- the degree of tension or clash versus compatibility perceived between the two cultures (e.g., I feel trapped between the two cultures" vs. "I do not see conflict between Chinese and American ways of doing things") (Q.-L. Huynh et al., 2012: 830).

Since cultural blendedness and cultural harmony are influenced by different contextual and personality variables, they function separately. Lower blendedness is related, for example, to lower openness to new challenges or higher barriers to second language acquisition, whereas lower cultural harmony is shaped by interpersonal traits such as higher neuroticism or greater perception of discrimination. Therefore, bicultural individuals may have any combination of the above cultural components.

My purpose in this paper is to take up the problematical conjunction of "Oriental" and "Occidental" rhetorical strategies which intersect in the discourse of bicultural authors. I am going to argue that differences between these two rhetorical styles are not based on "Oriental" writers subscribing to indirect and "Occidental" to direct styles of communication, but are rather based on discrete types of visual perception and face relationships one can adopt when participating in East-Asian and Western discourse. 


\section{Cultural differences in perception between West reality and East reality}

The relationship between language and the perception of reality was well captured long ago in the Whorfian hypothesis, which proposes that language and thought are inextricably tied together, determining the categories of perception open to the individual in a particular culture.

Since "perception is a cultural construct in which the actual world (empirical) is perceived as the real world (eidetic)" (Lanigan, 2012: 103), the actuality of bilingual writers is confronted by two separate, culture-specific constructs of reality that are not simply additive. The formation of such a bicultural authorial identity is the outcome of complex identification processes which equip a writer with several selves, interplaying with each other. In the case of Asian-American writers these selves are constituted by holistic, context oriented cognitive and social processes typical of East-Asian culture on the one hand, and the discrete and analogue perspective of Western cultures on the other.

The discrepancies in the cultural narratives of "Oriental" and "Occidental" authors are predominantly constituted by differences in visual perceptions of the East and the West. Lanigan (2012) divides these differences into two categories:

- W-reality (referring to a Western construction of perception)

- E-reality (referring to an Eastern construction of perception).

W-reality requires a cultural perspective which draws on the Geometric Linear Perspective based in occidental discourse. The Latin word occidere means to kill, to set (like the sun): the sun falls, sets in the West; perspective converges on a horizon point in space; horizon is a terminal point. Lanigan (2012) argues that the "isometric perspective" of the West demands the metaphysics of Phenomenalism, wherein Width $($ Horizontal $)+$ Height $($ Vertical $)=$ Depth $($ Diagonal $)$ and is a typical cultural perspective for $\mathrm{W}$-reality.
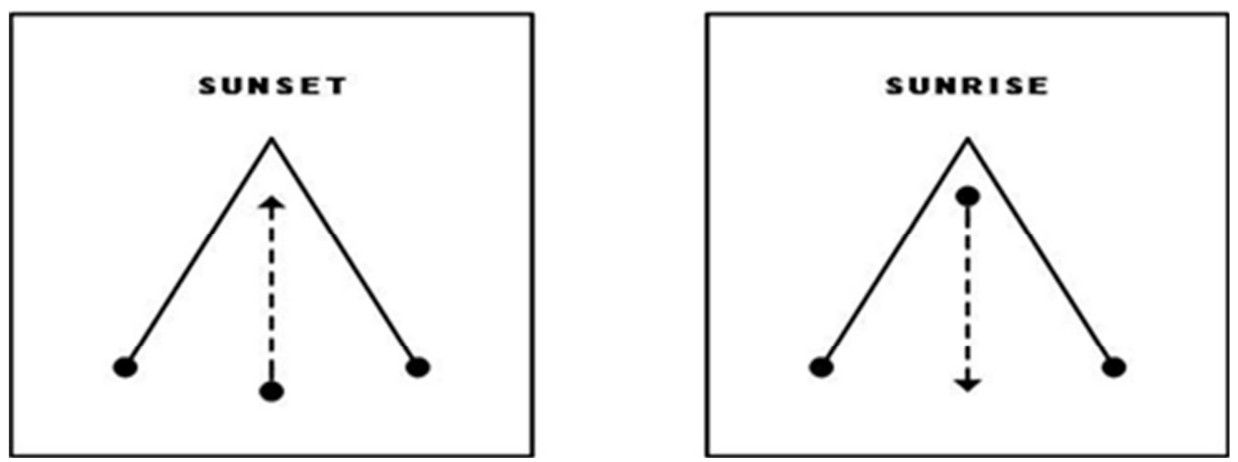

Fig. 1. The sun as a referent in actuality: Western sunset and Eastern sunrise (adapted from Lanigan, 2012) 
Conversely, E-reality is based on an Axonometric Curvilinear Perspective grounded in oriental discourse. The Latin word oriri means to rise, to arise: the sun stands, rises in the East; perspective emerges from a horizon point in space; the horizon is the point of origin. Lanigan (2012) explains that the "axonometric perspective" of the East utilizes the metaphysics of Phenomenology in which Depth $($ Diagonal $)=$ Height $($ Vertical $)+$ Width $($ Horizontal $)$ and is a characteristic cultural perspective for E-reality. Visual examples of the West and East constructions of perception in which the sun is a referent in actuality are shown in Figure 1.

These two different visual perspectives produce two different kinds of logic:

- Western logic draws on the "order of analysis"; demands a low-context perspective in which specific answers such as "guilty or not guilty"; "yes or no"; "right or wrong" are anticipated and therefore, is reductive (EITHER/OR type of reasoning).

- Eastern logic exhibits "order of experience"; requires a high-context perspective that can be exemplified by the following responses which are meant to signal "no": "I agree with you in principle," "I sympathize with you," "That needs further consideration" and thereby, is analogue (BOTH/AND type of reasoning) and expansive.

The conjunction of these contrasting perceptions creates a type of logic that features multi-dimensional and expansive thinking confronted by one- point concentration limited by reductive reasoning.

\section{The influence of different face systems and forms of discourse on authorial self-representation}

Two types of visual perception (W-reality and E-reality) and consequently, two kinds of logic (reductive and expansive) lead to discrete perceptions of self in East Asian and Western cultures. These differences in identity perception are additionally reinforced by the different face systems and forms of discourse which are made available to the members of both cultures.

The American sense of identity is strongly influenced by the individualistic cultural orientation. Although Americans exhibit a community spirit, in terms of working together for the benefit of the community, the predominant, national qualities are individuality, independence and self-reliance. It is only natural that Anglo-American discourse features linear organization and low-context argumentation, which reflect the values of a highly individualistic culture.

By comparison, the East Asian sense of self-awareness is shaped by interpersonal relations and exhibit a highly contextual and indirect communication style. The ancient Confucian kinship relationships are an extremely powerful 
force in East Asian social communication and are reiterated in teaching materials as the San Zi Jing (Xu Chuiyang, 1990), used today in public school books in East Asia.

Along these lines, the Chinese psychological anthropologist Francis L.K Hsu argues, "The major key (though never the only key) as to why we behave like human beings as well as to why we behave like Americans or Japanese is to be found in our relationships with our fellow human beings" (1983: 414). Hsu claims that human relations should constitute the basic unit of analysis in studies of identity and interpersonal communication. According to him (1985: 24), "the concept of personality is an expression of the western ideal of individualism. It does not correspond to the reality of how the western man lives in western culture, far less any man in any culture." For this reason, the idea of self that underlies western studies of communication, and tends to be highly individualistic, self-motivated, and open to ongoing negotiation, may not always be appropriate as a basis for studying East Asian discourse, which features a more collectivistic view of the self and is connected to one's membership in such basic groups as family, friends and co-workers. The East Asian collectivistic self is strongly influenced by assumed or unmarked assumptions about roles and responsibilities. This observation prompted Hsu to suggest that in the studies of East Asian discourse the idea of the individual self should be replaced by the Chinese concept of person (ren). Ren allows not only interior unconscious or preconscious ("Freudian") levels and expressible conscious levels of the person to be included in the analysis of identity, but also one's intimate society and culture. For example, in the analysis of the self based on ren, such relationships as those with one's parents and children are considered inseparable aspects of one's identity. The differences between the Chinese and the Western concepts of the self have been graphically presented by Hsu in two diagrams (see Figure 2 and 3).

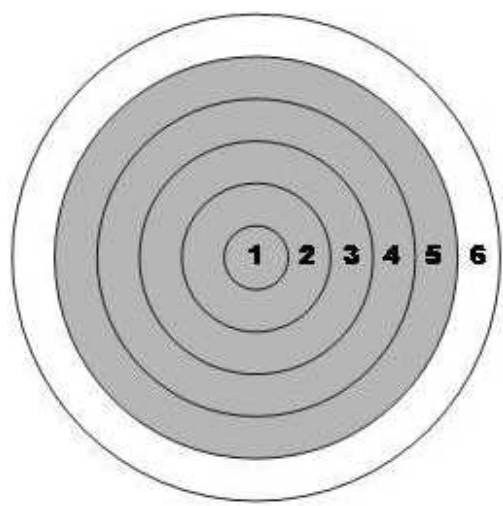

Key

6 Wider material culture

5 Intimate society and culture

4 Expressible conscious

3 Inexpressible conscious

2 Pre-conscious ("Freudian")

1 Interior unconscious

Fig. 2. The Chinese concept of the self (adapted from Hsu, 1983) 


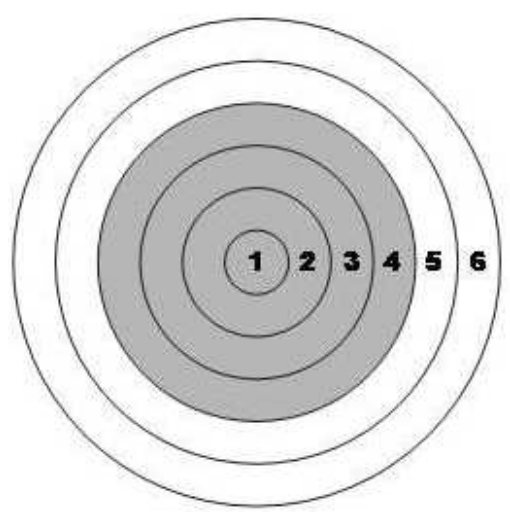

Key

6 Wider material culture

5 Intimate society and culture

4 Expressible conscious

3 Inexpressible conscious

2 Pre-conscious ("Freudian")

1 Interior unconscious

Fig. 3. The western concept of the self (adapted from Hsu, 1983)

In the American (individualistic) concept of the self, the boundary which defines the self is set up between the person and the person's immediate relationships, whereas the Chinese concept of person (ren) places the boundary of the person on the outside those intimate relations.

Hsu's aim in proposing the framework for the analysis of the self based on ren is not to offer an alternative to the individualistic concept of the self, but to argue that a socially separated individual is not real. Since intimate human relationships, as he asserts (1985: 34), "are literally as important as [a person's] requirement for food, water, and air", it is a dangerous analytical fiction to believe that the individual is the source of all social reality.

Considering the critical impact of social relations on the construction of the self, the concept of face becomes a key element in the discoursal analysis of the self in the socio-cultural perspective. Face is usually given the following definition: "Face is the negotiated public image, mutually granted each other by participants in a communicative event" (Scollon and Scollon, 2012: 47). Yet, this definition centres exclusively on the negotiation of face, leaving aside the assumptions participants bring to the communicative event. For the purpose of this paper, I will adhere to these two aspects of face. I believe that in any act of communication face is both negotiated and constituted by the assumptions discourse participants make before they enter a communicative event. What factors contribute to a desirable self- representation depends strongly on the way interlocutors organize discourses in their immediate relationships.

One of the most important aspects of face present in "Oriental" discourse is constituted by kinship. There are two major aspects of kinship which determine the nature of East-Asian discourse: hierarchical and collectivistic relationships.

Kinship relationships usually refer to blood bonds that define the obligations, rights and boundaries of interaction among its members. The primary relationships 
in "Oriental" cultures are not lateral relationships, like those between siblings, but hierarchical, like those between fathers and sons, mothers and daughters. From early childhood, children are taught to be obedient to their parents and are practiced in the discourse forms of hierarchical relationships. It is only natural that later in their lives they expect all relationships to feature hierarchical structures.

The other aspect of kinship important for discourse is that members of collectivistic relationships are not perceived as independent individuals, but as integral parts of hierarchies of kinship. The sense of identity and self-awareness are influenced by interpersonal relations based on filial piety, interdependence and shared aspirations to maintain group reputation, harmony and cohesion.

This preference for kinship relationships contrasts the emphasis on individualism and egalitarianism which reaches its extreme in American society. Kinship relationships are at odds with the American myth of the "self-made man" and are considered formidable obstacles to an individual's independence and progress. While participating in academic and other types of social discourses, American children are expected to show creativity and independence in thinking, along with problem-solving abilities.

This observation has been advanced by Hsu (1981) who notes that:

The [North] American emphasis on self-expression not only enables the [North] American child to feel unrestrained by the group, but also makes him [her] confident that he [she] can go beyond. The Chinese lack of emphasis on self-expression not only leads the Chinese child to develop a greater consciousness of the status quo but also serves to tone down any desire on his [or her] part to transcend the larger scheme of things (Hsu, 1981: 94).

The question of the influence of different face systems and forms of discourse on authorial self-representation is probably the most difficult issue to address in identity studies. One reason for this is that none of us are members of only one culture: people's identities are influenced (if not determined) by a variety of face systems and the forms of discourse in which we participate throughout our lives. Therefore, authorial identity becomes a compound of different selves which converge with each other in different ways depending on the social circumstances and forms of discourse. Another reason is that the knowledge of these face systems and forms of discourse is never complete, because of the multiplicity of discourse functions and their dynamic changes.

\section{Writing as the product of the writer's life history}

The study of writer identity construction continues to attract researchers from many disciplines. What binds them all together is the desire to understand how authors' autobiographical selves are influenced by their prior social and 
discoursal history and how this shapes the writer self-representation in discourse. The impact of the individual factors on the way writers present themselves in discourse is addressed in the social-cognitive model of identity construction, in which identity is defined as "[a] personal frame of reference for interpreting selfrelevant information, solving problems, and making decisions" (Berzonsky, 2011: 55). In this perspective, identity is approached from three different identity-processing orientations: informational, normative, and diffuse-avoidant which result from individual differences in identity styles.

The term 'autobiographical self' points to the link between writers' sense of their roots, their 'real self' and the way it is reconstructed in discourse. It is important to emphasize that the 'real self' is not a not a stable entity since it is subject to change as the writer develops (broadens knowledge and experience) and the context changes (e.g., when authors write across disciplines). This aspect of the authorial self is referred to by Bourdieu (1977) as the 'habitus': an individual's disposition to behave in certain ways. It gives a writer the agency to draw on unique social and linguistic resources, which allow them to resist undesirable subject positions and create new identities.

Since the 'autobiographical self' relates directly to a writer's life history, it is often viewed as the closest representation of what writers mean by their authorial identity. Yet it cannot be traced through any specific linguistic exponent and is revealed indirectly through two other aspects of a writer's identity, which I call the 'collective self' and 'self as performer.' In the model I proposed for authorial self-representation in academic text (Lehman, 2014: 604) the 'autobiographical self' along with 'self as performer' constitute the 'individual self' . The 'self as performer' is the writer's 'voice', in the sense that the writer's experience, position, opinions and beliefs are revealed by the particular stylistic choices a writer makes to establish authorial credibility, interaction with the audience and to show linguistic finesse. It is difficult to make categorical statements about the extent to which a writer's 'autobiographical self' influences the 'self as performer', since most of the time writers draw on their life histories subconsciously.

Furthermore, the 'individual self' determines and is determined by the prototypical possibilities for the "collective self ${ }^{2}$ available to a writer in the institutional and socio-cultural context in which they write.

\footnotetext{
${ }^{1}$ The 'individual self' is that aspect of the author's self, which is a product of their mind, cognition, personality and life history. It is constituted by the 'self as performer' and the 'autobiographical self.'

${ }^{2}$ The 'collective self' is that aspect of the author's self which is a social construct, constituted in the act of the writer's alignment with the conventions of dominant practices and discourses located in a particular institutional and cultural context.
} 
Most recently, the influence of a writer's autobiographical past on their authorial self-representation (referred to as 'narrative identity') has been plainly conceptualized within a new integrative theory of selfhood across the life course (McAdams and Cox, 2010) as "[t]he internalized and evolving story of the self that a person constructs to make sense and meaning out of his or her life" (McAdams, 2011: 99). Current interpretations of narrative identity emphasize the intricate interplay between culture and narrative, and suggest that “[a] person's life story says as much about the culture wherein a person's life finds its constituent meanings as it does about the person's life itself" (McAdams, 2011: 100). This perspective privileges a dynamic view of identity because throughout our lives we are socialized into different cultures which encompass both large (national, ethnic and religious) and small cultures (social groups and discourse communities individuals identify with). Therefore, following Ricoeur (1988: 22), “To answer the question 'Who?' ... is to tell the story of a life."

\section{The integration of bicultural identities}

Authors usually move between different social and cultural identities - some of which are more important than others; some of which they identify with and some of which they reject - and consequently occupy diverse subject positions. The plural form of the word captures the idea of people interacting simultaneously with several social groups, which means that identity is not a fixed concept but a continuous self-identification process which develops throughout the lifetime.

The way authors draw on these more or less compatible identities which constitute their authorial self becomes even more complex in the case of a bilingual writer, since the native socio-cultural framework is extended to include a second socio-cultural framework. These frameworks sometimes complement and sometimes oppose each other, leading to the construction of vague meanings, mental quandaries and frequently, identity conflict. It happens so, because language appears to be one of the most rooted elements of our identity and one which is easily identifiable by others. Like many other aspects of our identity, we take it for granted and we only reflect upon it when we feel our linguistic identity is being threatened.

Approximating the ideal of a successful second language writer often involves a fundamental shift in our views, norms and values, contributing to significant changes in our linguistic identity and even personality. Along these lines, Anna Wierzbicka, a Polish Australian linguist and academic, argues: 
[I] had to learn to 'calm down', to become less 'sharp' and less 'blunt', less 'excitable', less 'extreme' in my judgments, more 'tactful' in their expression. I had to learn the use of Anglo understatement (instead of the more hyperbolic and more emphatic Polish ways of speaking). I had to learn to avoid sounding 'dogmatic', 'argumentative', 'emotional' [...] But these weren't just changes in the patterns of communication. There were also changes in my personality. I was becoming a different person, at least when I was speaking English [...]Thus, I came to feel that by learning the Anglo ways I could enrich myself immeasurably, but I could also 'lose myself.' (Wierzbicka, 1997: 119-121)

The construction of the self of a bicultural author not only involves the rhetorical adjustments mentioned in the above quote, but it also requires significant changes in the 'semantic matrix' people impose on the world in order to make sense. Eva Hoffman, a Polish American writer and academic, provides the following description of the 'conceptual grid' shift she experienced:

But mostly, the problem is that the signifier has become severed from the signified. The words I learn now don't stand for things in the same unquestioned way they did in my native tongue. "River" in Polish was a vital sound, energized with the essence of riverhood, of my rivers, of my being immersed in rivers. "River" in English is cold a word without aura. It has no accumulated associations for me, and it does not give off the radiating haze of connotation. It does not evoke. (Hoffman, 1989: 106)

Hoffman's personal experience of an émigré who was made to translate her sense of self into a new culture and a new language demonstrates clearly the arbitrary nature of the relationship between a symbol and its referent. Since the thing/concept signified is created in an individual's mind on the basis of their knowledge and experience, it is unique for each person.

Any text, whether literary or academic, "is a social performance achieved by drawing on appropriate linguistic resources" (Hyland, 2009: 70). Identity is, therefore, seen as both constructing (due to the agency of the writer) and being constructed (by social structures and social practices) in discourse. Clearly, for effective reader-writer communication to occur, authors must move their identity from the personal to the social sphere and from the inner processes of cognition to the outer dynamic and interactive construction in a text.

The primary outer factor which influences authorial self-representation is culture. The rhetorical and linguistic choices available to a writer are constrained by the value and belief systems prevailing in the linguistic and cultural community of the author. A writer's understanding of what appealing prose or persuasive writing looks like is constituted in the process of socialization into the native writing convention. The schemata acquired and constructed through native socio-cultural experiences are resistant to change (for they are supposedly subconscious and hardly ever questioned) and hence, exert a lifelong impact on a writer's perception of 'good writing.' 
For example, the Chinese concept of the self makes it difficult for Chinese writers to be direct and assertive in their statements. According to Scollon (1991), the Confucian values which constitute the Chinese self are based on four central relationships: affection between parent and child, righteousness between ruler and ruled, differentiation between elder and younger, and trust between friend and friend. These values affect the choice of a particular writing style which features "[a] restricted expression of personal feelings and views, an indirect approach to the chosen topic, and a preference for prescribed, formulaic language" (Cai, 1993: 11). Conversely, the writing style of the West emphasizes the voice of the individual writer and is in line with the Western notion of selfness based on the idea of individualism. This leads to directness of assertions including unambiguous expressions of feelings and beliefs.

\section{The case of Amy Tan}

The impact of the exposure to two different types of English (one used at home and the other at school) and two face systems (American and Chinese) is evidenced in the literary output of Amy Tan, who was born in the US to immigrant parents from China. Even though she has always had a love for language, what led her to write was her militant attitude and determination to prove that she could write in English, despite the limitations imposed on her by her cultural background. She wrote, "[I] happen to be rebellious and enjoy the challenge of disproving assumptions about me. I became an English major my first year in college, after being enrolled as pre-med" (Tan, 2008: 163). Because of her unique background, she created her authorial voice by drawing on two major influences: her Chinese-American cultural experience and her mother-daughter relationship.

To construct her authorial self (the voice she wanted her readers to hear) Tan decided to reconcile the requirements of plain Anglo-American rhetoric (grounded in an individualistic concept of the self) with an East-Asian expansive logic (based in a collectivistic view of one's identity). She described these efforts in her essay "Mother Tongue", which I will strongly draw on here to demonstrate how the different Englishes she grew up contributed to her identity.

Tan's mother was the major influence on the language of her writing, and their relationship became the major theme of her novels. This reflects the importance of hierarchical relationships, like those between mothers and daughters, in Chinese culture. Her mother was the major critic of her literary output, more important than her American audience. This can be illustrated by Tan's description of one of her meetings with her readers: 
The talk was about my writing, my life, and my book The Joy Luck Club, and it was going along well enough, until I remembered one major difference that made the whole talk sound wrong. My mother was in the room. And it was perhaps the first time she had heard me give a lengthy speech, using the kind of English I have never used with her [...] a speech filled with carefully wrought grammatical phrases, burdened, it suddenly seemed to me, with nominalized forms, past perfect tenses, conditional phrases, forms of standard English that I had learned in school and through books, the forms of English I did not use at home with my mother. (Tan, 2008: 160-161)

The English they used with each other drew on their Chinese cultural heritage. It was the language of intimacy, a different sort of English dedicated to family talk. Although some of Tan's American friends said they understood none of her mother's English, as if she were speaking pure Chinese, to Tan it was perfectly clear and natural. She wrote, "[I]t's my mother tongue. Her language, as I hear it, is vivid, direct, full of observation and imagery. That was the language that helped shape the way I saw things, expressed things, made sense of the world" (Tan, 2008: 161). Therefore, when Tan decided to become a writer and envisage the reader of her stories, she chose her mother:

So with this reader in mind I began to write stories using all the Englishes I grew up with: the English I spoke to my mother, which for lack of a better term might be described as "simple"; the English she used with me, which for lack of better term might be described as "broken"; my translation of her Chinese, which could certainly be described as "watered down"; and what I imagined to be her translation of her Chinese if she could speak in perfect English, her internal language, and for that I sought to preserve the essence, but neither an English nor a Chinese structure. I wanted to capture what language ability tests could never reveal: her intent, her passion, her imagery, the rhythms of her speech and the nature of her thoughts. (Tan, 2008: 163)

During Tan's school years, English was never her strong suit because she could not align herself with the linear, reductive logic required on English tests. For her, the answers in English tests were always a judgment call, a matter of opinion and personal experience. Since the perception of relevance is culturally determined, the textual and linguistic features which make English prose relevant differ significantly from the requirements for coherence and logic in other cultures. Tan provides the following explanation of the lack of 'relevance' in her answers on English tests:

Those tests were constructed around items like fill-in-the blank sentence completion, such as "Even though Tom was Mary thought he was_.." And the correct answer always seem to be the most bland combinations, for example, "Even though Tom was shy, Mary thought he was charming," with the grammatical structure "Even though" limiting the correct answer to some sort of semantic opposites, so you wouldn't get answers like "even though Tom was foolish, Mary thought he was ridiculous." Well, according to my 
mother and me, there were very few limitations as to what Tom could have been and what Mary might have thought of him. So I never did well on tests like that.

The same was true with word analogies, pairs of words for which you were supposed to find some logical semantic relationship, for instance, "Sunset is to nightfall as _ is to _.." And here you would be presented with a list of four possible pairs, one of which showed the same kind of relationship: red is to stoplight, bus is to arrival, chills is to fever, yawn is to boring. Well, I could never think that way. I knew what the tests were asking, but I could not block out of my mind the images already created by the first pair, sunset is to nightfall- and I could see the burst of colors against a darkening sky, the moon rising, the lowering of a curtain of stars. And all the other pairs of words [...] just threw up a mass of confusing images, making it impossible for me to see that saying "A sunset proceeds nightfall" was as logical as saying "A chill proceeds a fever." The only way I would have gotten that answer right was to imagine an associative situation, such as my being disobedient and staying out past sunset, catching a chill at night, which turned into feverish pneumonia as punishment - which indeed did happen to me. (Tan, 2008: $162-163$ )

\section{Conclusions}

Today the emergence of the plural forms of English broadly acknowledges differences in the sociolinguistic realities of bicultural writers. The degree of writer conformity in adjusting to the specific rhetorical and linguistic requirements of so-called Standard English has significantly decreased. This has been demonstrated by new developments in merging the stylistic features of the Hausa language with English in West Africa, and the legitimization of localized models of English in China which include Chinese Pidgin, New Chinese Pidgin, Chinglish, Chinese English and China English.

The case of Amy Tan shows the need to legitimize the voices from one cultural context within a new cultural context. The major theoretical concept behind her writing is that voice is realized not through isolated features of language but through the relationship between sociocultural context and text-level orientations to the subject matter, authorial engagement and the method of development, which are referred to as experiential, interpersonal and textual meanings within Systemic Functional Linguistics (SFL).

For skilled bicultural writers, the content of their writing, what they consider as acceptable and reasonable evidence and how they structure their work is influenced by their prior writing experiences in their first culture. In order to use these experiences as assets, not obstacles in academic communication, the legitimization of variant forms of English, combining features of both the source and target cultures has become a necessity we can ill-afford to ignore. It is therefore clear that an important line of further research in the fields of discourse studies, 
textual linguistics and cultural studies should focus on the construction of a theoretical and methodological framework for establishing the sociocultural and linguistic factors that would enable the acceptance of alternative voices in Anglo-American discourse.

\section{References}

Berzonsky, M.D. 2011. "Processes of personal identity formation and evaluation". In: Schwartz, J.S., Luyckx, K. and V.L. Vignoles. (eds). Handbook of identity theory and research. Berlin: Springer-Verlag. 55-76.

Bourdieu, P. 1977. Outline of a theory of practice. Philadelphia, PA: Temple University Press.

Cai, G. 1993. "Beyond bad writing: teaching English composition to Chinese ESL students". Paper presented at the College Composition and Communication Conference. San Diego, CA, March 1993.

Gee, J.P. 1999. An introduction to discourse analysis: theory and method. London/New York: Routledge.

Hoffman, E. 1989. Lost in translation. New York: Dutton.

Hsu, F.L.K. 1981. Americans and Chinese: passages to differences. 3rd ed. Honolulu: University of Hawaii Press.

Hsu, F.L.K. 1983. Rugged individualism reconsidered: essays in psychological anthropology. Knoxville: University of Tennessee Press.

Hsu, F.L.K. 1985. "The self in cross-cultural perspective". In: Marsella, A.J., DeVos, G. and F.L.K. Hsu. (eds). Culture and self: Asian and western perspectives. New York: Tavistock Publications. 24-55.

Hyland, K. 2009. Academic discourse: English in a global context. London: Continuum.

Lanigan, R.L. 2012. "Contact confusion in perception: West meets East, one actuality becomes two realities". In: Chruszczewski, P.P., Rickford, J.R., Buczek, K., Knapik, A.R. and J. Mianowski. (eds). Languages in contact 2012. Wrocław: Wydawnictwo Wyższej Szkoły Filologicznej we Wrocławiu. 103-125.

Lehman, I.M. 2014d. "The co-construction of authorial identity in student writing in Polish and English”. In: Grucza, S., Anajjar, J., Borowska, A. and M. Płużyczka. (eds). Studi@Naukowe 25. Warszawa: Wydawnictwo Naukowe Instytutu Kulturologii i Lingwistyki Antropocentrycznej UW.

McAdams, D.P. and K.S. Cox. 2010. "Self and identity across the life span". In: Lerner, R., Freund, A. and M. Lamb. (eds). Handbook of lifespan development. Vol. 2. Cambridge/New York: Cambridge University Press. 158-207.

McAdams, D.P. 2011. "Narrative identity". In: Schwartz, S.J., Luyckx, K. and V.L. Vignoles. (eds). Handbook of identity theory and research. Berlin: Springer-Verlag. 99-115.

Huynh, Q.L., Nguyen, A-M., Tu, D. and V. Benet-Martínez. 2011. "Bicultural identity integration". In: Schwartz, S.J., Luyckx, K. and V.L. Vignoles. (eds). Handbook of identity theory and research. Berlin: Springer-Verlag. 827-842.

Ricoeur, P. 1988. Time and narrative III (Translated by Kathleen Blarney and David Pellauer). Chicago: The University of Chicago Press.

Scollon, R. 1991. "Eight legs and one elbow: Stance and structure in Chinese English compositions". In: Proceedings of the Second North American Conference on Adult and Adolescent Literacy. Hong Kong.

Scollon, R., Wong Scollon, S. and R.H. Jones. 2012. Intercultural communication: a discourse approach. 3rd ed. London: Wiley-Blackwell. 
Tan, A. 2008. "Mother tongue". In: Silberstein, S., Dobson, B.K. and M.A. Clarke. (eds). Reader's choice. $5^{\text {th }}$ ed. Michigan: The University of Michigan Press. 160-163.

Wierzbicka, A. 1997. "The double life of a bilingual: a cross-cultural perspective". In: Bond, M.H. (ed.). Working at the interface of cultures. Eighteen lives in social science. London: Routledge. 113-125.

Xu, C. (ed.). 1990. The three character classic in picture. Singapore: EPB Publishers. 